\title{
Properties of Cementitious Composites Containing Active/Inter Mineral Admixtures
}

\author{
Pingchuan Wu${ }^{1}$, Changlong Wang ${ }^{2,1,3 *}$, Yapeng Zhang ${ }^{1 *}$, Lie Chen ${ }^{1}$, Wei Qian ${ }^{1}$, \\ Zhenyu Liu', ChangZhi Jin', Li Li ${ }^{1}$ \\ ${ }^{1}$ School of Civil Engineering, Hebei University of Engineering, Handan Hebei Province, 056038, China \\ ${ }^{2}$ Jiangxi Key Laboratory of Mining Engineering, Jiangxi University of Science and Technology, \\ Ganzhou Jiangxi Province 341000, China \\ ${ }^{3}$ Tianjin Sunenergy Sega Environmental Science and Technology Co. Ltd, Tianjin 300000, China
}

Received: 24 April 2017

Accepted: 19 August 2017

\begin{abstract}
Fly ash and ground iron ore tailings with fineness similar to cement were used as active and inert mineral admixtures in this study. This paper examines the compressive strength development of plain mortar and blend mortar containing fly ash and ground iron ore tailing. The mortar was cured at the same curing regime and a different water to cementitious material ratio was used. The autogenous shrinkage is also detected in the first seven days. At the early stage of hydration, fly ash and ground iron ore tailings played a role as physical filler during the hydration of the cementitious composites. As age increases, the pozzolanic reaction of fly ash became dramatic. Concrete with fly ash and ground iron ore tailings has a similar trend of autogenous shrinkage. As the amount of fly ash and ground iron ore tailings increases, autogenous shrinkage linearly decreases and their autogenous shrinkage is similar to each other. The autogenous shrinkage of concrete in one day is more than the total shrinkage of $80 \%$ in seven days.
\end{abstract}

Keywords: fly ash, iron ore tailings powder, compressive strength, autogenous shrinkage, physical filler effect

\section{Introduction}

As a new type of high-tech concrete, highperformance concrete (HPC) represents the future of concrete technology as its durability has obtained a dramatic improvement compared to traditional concrete, which shows that concrete has marched toward hightech materials [1-4]. Mineral admixtures have become the sixth essential component for high-tech concrete, in which fly ash is the most widely used mineral admixture.

*e-mail: 13716996653@139.com,1841621865@qq.com
Fly ash can reduce bleeding of fresh concrete, lower the hydration heat, and improve the durability of concrete and its long-term strength [5-7]. A study by Shen et al. [8] in 1981 indicated that "the effects of fly ash" included the micro-filler, particle shape, and pozzolanic effects. Of the above three effects, the first two belong to physical effects while the last one is a chemical effect by the pozzolanic reaction of the active component in fly ash [9]. In the early age of concrete, fly ash has a low activity and it only shows the physical effects, while it shows a dramatic long-term chemical effect [10]. Different studies on the hydration of fly ash blending cementitious materials show that the hydration of fly ash at an early age can be neglected 
[11-15]. Park et al. [16] and Wang [17] studied the activity of fly ash. They improved the activity of fly ash by adding a chemical activator. The studies by Mehta [18], Payá et al. [19], Lee et al. [20], and Shaikh et al. [21] indicate that the micro-filler effect of fly ash has a great influence on the mechanical properties of cementitious composites.

The above summary shows that the micro-filler and pozzolanic effects of fly ash have been widely studied. However, there are very few studies about the application of ground iron ore tailings into concrete and how that influences concrete properties. This paper will examine the influence of fly ash and ground iron ore tailings on the properties of composite cementitious materials.
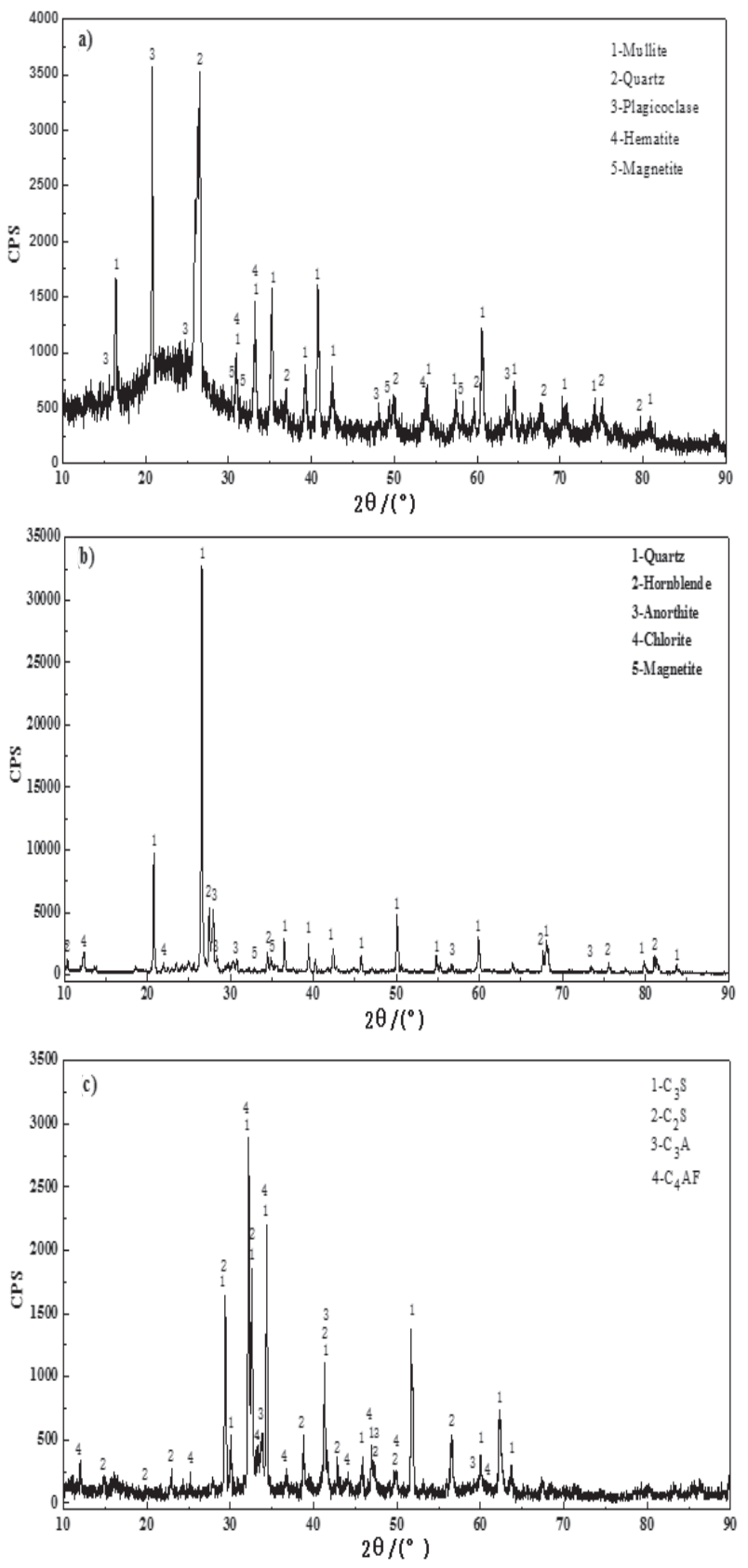

Fig. 1. Mineralogical phases of cement and mineral admixtures: a) fly ash, b) iron ore tailings, c) cement.

\section{Material and Methods}

\section{Materials}

- Class I fly ash from Shijingshan power plant. Its water demand is $92 \%$ and its chemical composition is shown in Table 1 . The main mineral phases include mullite and quartz, while there is a large amount of amorphous phase, as shown in Fig. 1a).

- Iron ore tailings from Dashihe iron ore. After precipitation, drying, mixing, and dividing, the iron ore tailing sample was obtained and its chemical composition is shown in Table 1. The amount of $\mathrm{SiO}_{2}$ is higher than $70 \%$, which indicates that the tailings belong to high silicon iron ore tailing. The main mineral phase is quartz, while the minor phases are hornblende, anorthite, and chlorite, as shown in Fig. 1b). More than $90 \%$ of particles are smaller than $0.63 \mathrm{~mm}$, of which $16 \%$ are smaller than $0.10 \mathrm{~mm}$. Our tailings became powder after 30 mins grinding in a ball mill (SM $\Phi 500 \times 500,5 \mathrm{~kg})$.

- P.O. 42.5 cement was used in this study. Its chemical composition and physical properties are shown in Tables 1 and 2. Fig. 1c) shows its mineral components to be $48.92 \% \mathrm{C}_{3} \mathrm{~S}, 29.61 \% \mathrm{C}_{2} \mathrm{~S}, 7.73 \% \mathrm{C}_{3} \mathrm{~A}$, and $8.83 \%$ $\mathrm{C}_{4} \mathrm{AF}$ by mass.

- Others: The coarse aggregate for concrete is crushed limestone with a size range of $5-25 \mathrm{~mm}$. The fine aggregates are sand with a fineness modulus of 2.8 and mud content less than 3\%. UNF-5 water reducer was also used, and ISO sand was used in the mortar preparation.

We used a laser particle size analyzer (MASTER SIZER 2000, detection range: 0.02 2000.00 $\mu \mathrm{m}$ ) to analyze the particle distribution of IOTP, fly ash, and cement, as shown in Fig. 2. There is slightly lower particle content between $0.1 \sim 15 \mu \mathrm{m}$ in fly ash than that in IOTP, while fly ash has a slightly higher content of particles larger than $15 \mu \mathrm{m}$ than IOTP. Thus, it can be implied that fly ash is slightly coarser than IOTP. Cement has the greatest fineness among fly ash, IOTP, and cement.

Field emission scanning electron microscopy (FESEM) was used to observe the particle shapes of fly ash and ground IOTP, as shown in Fig. 3. Fig. 3a) shows the smooth and round shape of amorphous particles, and the black spots on some particles may be residual carbon. Fig. $3 \mathrm{~b}$ shows the sharp irregular polyhedral shapes of IOTP, of which some particles are long stripes. Meanwhile, some fine particles agglomerate with each other or are attached to the surface of the large particles [22].

\section{Methods}

The titrimetric analysis method was adopt to chemical composition analysis of materials. Specific amounts of fly ash, IOTP, cement, and ethanol solutions were measured using an electrical balance (Shuangjie, JJ-1000). After mixing well, the mixture of powder and ethanol solution was dispersed using an ultrasonic disperser 
Table 1. Chemical composition of cement and mineral admixtures (\%).

\begin{tabular}{|c|c|c|c|c|c|c|c|c|c|}
\hline Materials & $\mathrm{SiO}_{2}$ & $\mathrm{Al}_{2} \mathrm{O}_{3}$ & $\mathrm{Fe}_{2} \mathrm{O}_{3}$ & $\mathrm{FeO}$ & $\mathrm{MgO}$ & $\mathrm{CaO}$ & $\mathrm{Na}_{2} \mathrm{O}_{\text {equi }}$ & $\mathrm{SO}_{3}$ & Loss \\
\hline Fly ash & 54.80 & 13.12 & 6.28 & 1.32 & 1.82 & 18.43 & 0.78 & 0.37 & 3.01 \\
\hline Iron ore tailings powder & 71.21 & 5.04 & 10.62 & 3.96 & 1.84 & 3.22 & 0.32 & 0.23 & 2.88 \\
\hline Cement & 22.15 & 4.86 & 3.43 & 0.54 & 0.83 & 64.30 & 0.23 & 0.31 & 2.96 \\
\hline
\end{tabular}

$\mathrm{Na}_{2} \mathrm{O}_{\text {equi }}=\mathrm{Na}_{2} \mathrm{O}+0.658 \mathrm{~K}_{2} \mathrm{O}$

Table 2. Physical properties of the cement.

\begin{tabular}{|c|c|c|c|c|c|c|c|c|}
\hline \multirow{2}{*}{$\begin{array}{c}\text { Normal } \\
\text { consistency }(\%)\end{array}$} & \multirow{2}{*}{$\begin{array}{c}\text { Specific surface } \\
\text { area }\left(\mathrm{m}^{2} \cdot \mathrm{kg}^{-1}\right)\end{array}$} & \multicolumn{2}{|c|}{ Setting time (minutes) } & \multirow{2}{*}{ Stability } & \multicolumn{2}{|c|}{$\begin{array}{c}\text { Flexural strength } \\
\text { (MPa) }\end{array}$} & \multicolumn{2}{c|}{$\begin{array}{c}\text { Compressive strength } \\
(\mathrm{MPa})\end{array}$} \\
\cline { 7 - 10 } & & $\begin{array}{c}\text { Initial } \\
\text { setting }\end{array}$ & Final setting & & $3 \mathrm{~d}$ & $28 \mathrm{~d}$ & $3 \mathrm{~d}$ & $28 \mathrm{~d}$ \\
\hline 26.4 & 365 & 90 & 210 & qualified & 5.4 & 8.6 & 20.7 & 52.9 \\
\hline
\end{tabular}

(Toshiba, SB-5200). Then the dispersed mixture was moved into the laser particle size analyzer. The particle size distribution test was operated based on GB/T19077.12008. XRD analysis was performed on the materials by a Rigaku D/MAX-RC $12 \mathrm{KW}$ rotating anode XRD diffractometer with rotating $\mathrm{Cu}$, a wavelength of 1.5406 $\mathrm{mm}$, working current of $150 \mathrm{~mA}$, and working voltage of $40 \mathrm{kV}$. FESEM observation was performed to analyse the formation of fly ash and IOTP using a Zeiss SUPRA 55 scanning electron microscope coupled with a Be4-U92 energy spectrum.

Table 3. Composition and mix proportions of complex binders.

\begin{tabular}{|c|c|c|c|c|}
\hline \multirow{2}{*}{ Sample } & \multirow{2}{*}{ w/b } & \multicolumn{3}{|c|}{ Mix proportion (by mass; \%) } \\
\cline { 3 - 5 } & & Cement & $\begin{array}{c}\text { Iron ore tailings } \\
\text { powder }\end{array}$ & Fly ash \\
\hline C0HW & 0.48 & 100 & - & - \\
\hline T0HW & & 70 & 30 & - \\
\hline F0HW & & 70 & - & 30 \\
\hline T1HW & & 50 & 50 & - \\
\hline F1HW & & 50 & - & 50 \\
\hline C0MW & 0.42 & 100 & - & - \\
\hline T0MW & & 70 & 30 & - \\
\hline F0MW & & 70 & - & 30 \\
\hline T1MW & & 50 & 50 & - \\
\hline F1MW & & 50 & - & 50 \\
\hline C0LW & 0.34 & 100 & - & - \\
\hline T0LW & & 70 & 30 & - \\
\hline F0LW & & 70 & - & 30 \\
\hline T1LW & & 50 & 50 & - \\
\hline F1LW & & 50 & - & 50 \\
\hline
\end{tabular}

The compressive strength test for mortar was operated based on GB/T 17671-1999. The mixture proportions (by mass) are listed in Table. 3. The dimension of samples is $40 \times 40 \times 160 \mathrm{~mm}$. The samples were moist-cured to specific ages and then the compressive strength was measured.

The autogenous shrinkage of concrete was measured with a contactless concrete shrinkage strain gauge (CABR-NES, precision: $\pm 1 \mu \mathrm{m} / \mathrm{m}$ ) according to the procedure in [23]. The gauge automatically collected the shrinkage data for 169 hours after initial setting. The mixture proportions of concrete are listed in Table 4.

\section{Results and Discussion}

\section{The Strength of Mortar}

Fig. 4 shows the compressive strength of mortar with $\mathrm{w} / \mathrm{b}=0.48,0.42$, and 0.34 at the ages of $1,3,7,28,90$, and 180 days. It can be observed that $\mathrm{w} / \mathrm{b}$, the type and mineral admixtures and the dosage of mineral admixtures greatly influence the compressive strength of composite mortars. Within the age of seven days, there is similar compressive strength in the concrete with fly ash and IOTP, while strength development is also similar. For the fly ash and IOTP blend concrete with $\mathrm{w} / \mathrm{b}=0.34$ and a replacement level of $30 \%$, they still have similar strength development trend as aging. For the fly ash blend concrete with a replacement level of $50 \%$, the compressive strength keeps increasing, and its compressive strength at the age of 180 days is close to that of plain concrete. Meanwhile, the compressive strength has stopped increasing in the IOTP blend concrete.

As shown in Fig. 4, as the w/b decreases from 0.48 to 0.34 , the compressive strength of the mortar specimens increases. As the replacement level of fly ash and IOTP increases, compressive strength decreases. At the early stage of hydration, fly ash and IOTP can be treated as inert admixtures due to the low degree of reaction. Their presence in reality increases the actual water to cement ratio in the system, which helps increase the degree of 
Table 4. Mix proportion of concrete.

\begin{tabular}{|c|c|c|c|c|c|c|c|c|}
\hline \multirow{2}{*}{ Sample } & \multirow{2}{*}{$\mathrm{w} / \mathrm{b}$} & \multicolumn{7}{|c|}{ Compositions (by mass) of concrete $\left(\mathrm{kg} / \mathrm{m}^{3}\right)$} \\
\hline & & Cement & Iron ore tailings powder & Fly ash & Sand & Stone & Water & UNF-5 \\
\hline COAS & 0.25 & 500 & - & - & 621 & 1,154 & 125 & 3 \\
\hline T0AS & & 450 & 50 & - & 621 & 1,154 & 125 & 3 \\
\hline F0AS & & 450 & - & 50 & 621 & 1,154 & 125 & 3 \\
\hline T1AS & & 400 & 100 & - & 621 & 1,154 & 125 & 3 \\
\hline F1LS & & 400 & - & 100 & 621 & 1,154 & 125 & 3 \\
\hline T2AS & & 350 & 150 & - & 621 & 1,154 & 125 & 3 \\
\hline F2AS & & 350 & - & 150 & 621 & 1,154 & 125 & 3 \\
\hline COMS & 0.30 & 500 & - & - & 614 & 1,136 & 150 & 2.7 \\
\hline T0BS & & 450 & 50 & - & 614 & 1,136 & 150 & 2.7 \\
\hline F0BS & & 450 & - & 50 & 614 & 1,136 & 150 & 2.7 \\
\hline T1BS & & 400 & 100 & - & 614 & 1,136 & 150 & 2.7 \\
\hline F1BS & & 400 & - & 100 & 614 & 1,136 & 150 & 2.7 \\
\hline $\mathrm{T} 2 \mathrm{BS}$ & & 350 & 150 & - & 614 & 1,136 & 150 & 2.7 \\
\hline F2BS & & 350 & - & 150 & 614 & 1,136 & 150 & 2.7 \\
\hline $\mathrm{COCS}$ & 0.35 & 500 & - & - & 604 & 1,121 & 175 & 2.4 \\
\hline T0CS & & 450 & 50 & - & 604 & 1,121 & 175 & 2.4 \\
\hline F0CS & & 450 & - & 50 & 604 & 1,121 & 175 & 2.4 \\
\hline T1CS & & 400 & 100 & - & 604 & 1,121 & 175 & 2.4 \\
\hline F1CS & & 400 & - & 100 & 604 & 1,121 & 175 & 2.4 \\
\hline $\mathrm{T} 2 \mathrm{CS}$ & & 350 & 150 & - & 604 & 1,121 & 175 & 2.4 \\
\hline $\mathrm{F} 2 \mathrm{CS}$ & & 350 & - & 150 & 604 & 1,121 & 175 & 2.4 \\
\hline
\end{tabular}

hydration [9]. There is a higher porosity in the cementitious materials with a high $\mathrm{w} / \mathrm{b}$, which is a benefit in increasing

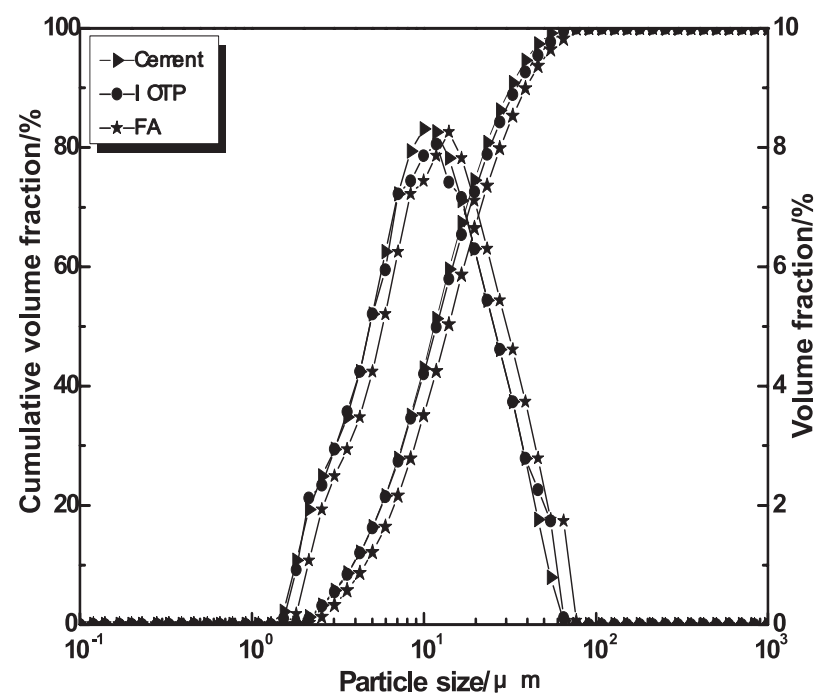

Fig. 2. Particle distribution of cement, fly ash, and iron ore tailings. the relative amount of hydration products, densifying the matrix, and thus increasing the compressive strength. At $\mathrm{w} / \mathrm{b}=0.48$, compared to $\mathrm{C} 0 \mathrm{HW}$ (plain cement), the hydration of cement tends to stop in FOHW (30\% instead of cement with fly ash) and TOHW (30\% instead of cement with IOTP) with a mineral admixture replacement level of $30 \%$ at the longer age. This results in the stabilization of the porosity, thus the compressive strength tends to stop. The compressive strength of F0HW and F1HW

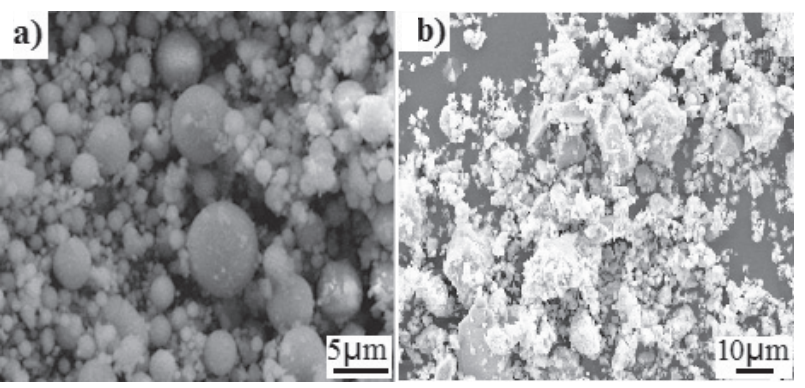

Fig. 3. Morphologies of mineral admixture powders: a) fly ash, b) iron ore tailings powder. 
(50\% instead of cement with fly ash) accounts for $105 \%$ and $88 \%$ that of $\mathrm{COHW}$. This is due to the pozzolanic reaction further decreasing internal porosity and thus the compressive strength keeps increasing. At w/b $=0.34$ and the mineral admixture replacement level of $30 \%$, the initial porosity of the mortar samples is higher than that in the mortars with a w/b of 0.48 , and the filling effect of hydration products in the internal pores becomes
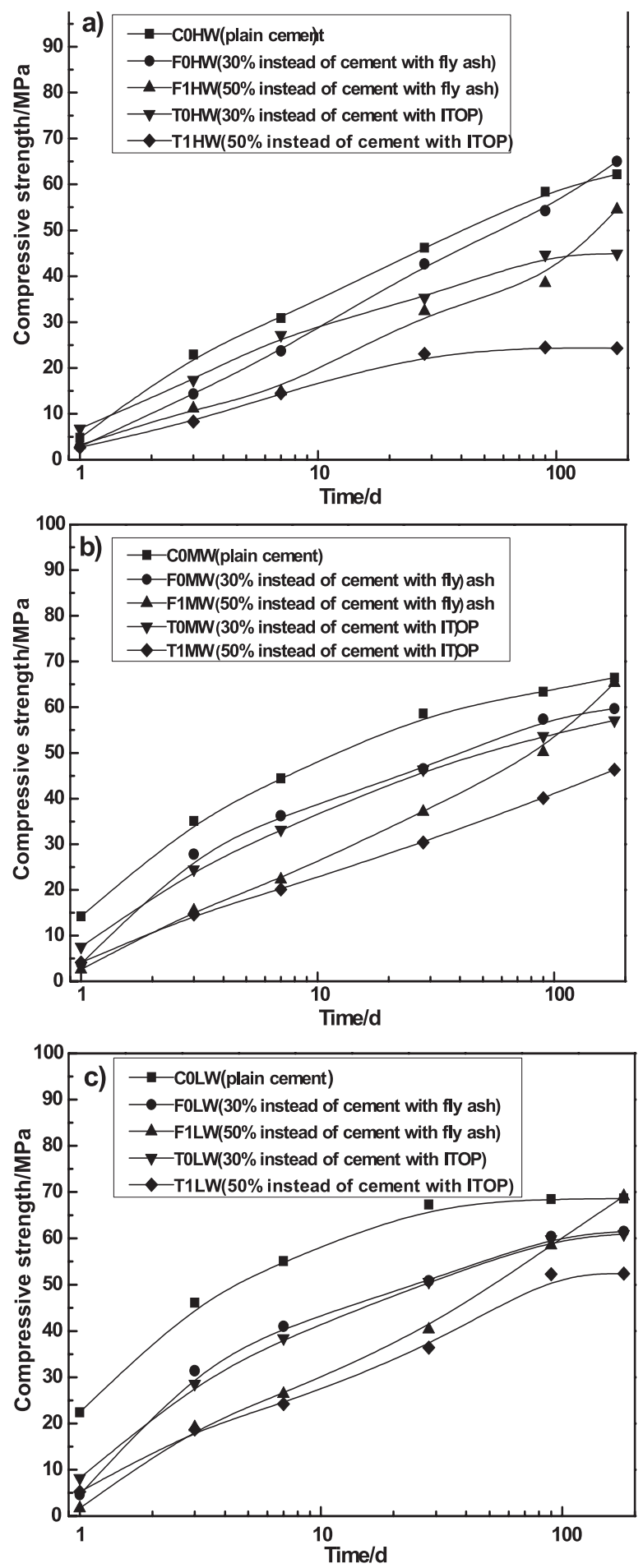

Fig. 4. Compressive strength development of cement mortar samples cured in standard conditions: a) w/b $=0.48, \mathrm{~b}$ ) $\mathrm{w} / \mathrm{b}=0.42, \mathrm{c}) \mathrm{w} / \mathrm{b}=0.34$. smaller. Thus, there is a similar trend for compressive strength development within the age of 180 days. When the replacement level is $50 \%$, there is a large porosity of mortar samples and the relative amount of cement is low, which results in the formation of fewer hydration products and a lower compressive strength. As an inert mineral admixture, the addition of IOTP in T1LW $(50 \%$ instead of cement with IOTP) can bring in more hydration
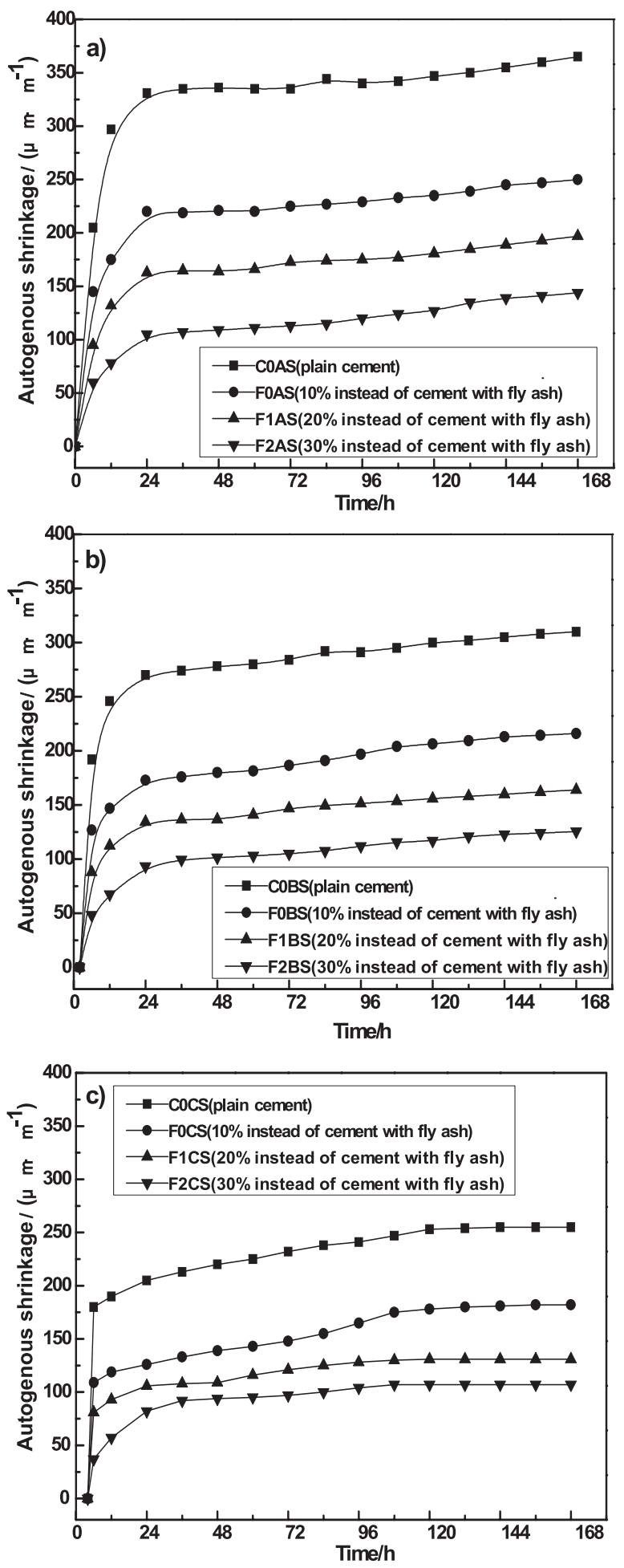

Fig. 5. Autogenous shrinkage curves of fly ash concrete: a) $\mathrm{w} / \mathrm{b}=0.25, \mathrm{~b}) \mathrm{w} / \mathrm{b}=0.30, \mathrm{c}) \mathrm{w} / \mathrm{b}=0.35$. 
products itself, thus there is no increase in compressive strength. However, due to the pozzolanic reaction of fly ash in F1LW (50\% instead of cement with fly ash), there are new hydration products from fly ash, which densifies the microstructure of mortar samples and leads to further increasing compressive strength [9].
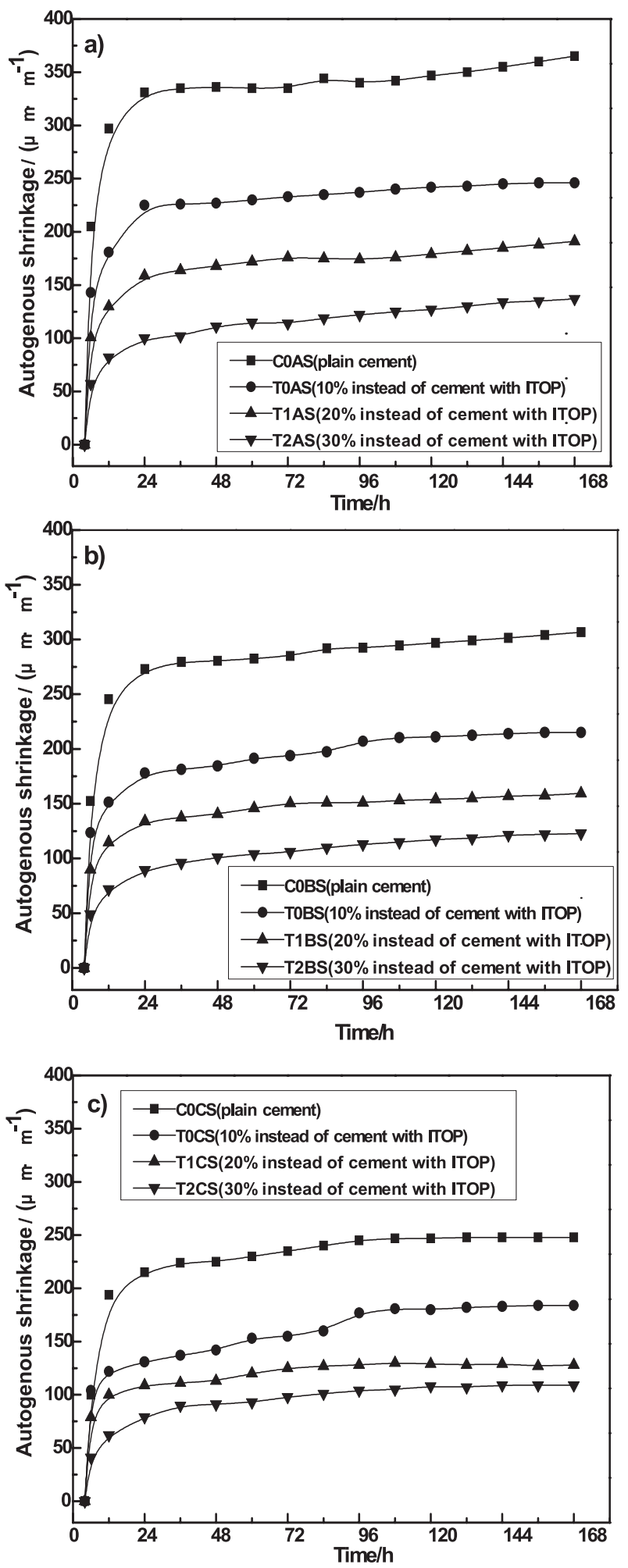

Fig. 6. Autogenous shrinkage curves of iron ore tailings powder concrete: a) $\mathrm{w} / \mathrm{b}=0.25, \mathrm{~b}) \mathrm{w} / \mathrm{b}=0.30, \mathrm{c}) \mathrm{w} / \mathrm{b}=0.35$.
As indicated in Fig. 4, fly ash and IOTP have an obvious influence on the long-term compressive strength only if the replacement level is large. When the replacement level is $30 \%$, the addition of fly ash and IOTP has no influence on compressive strength. As an inert mineral admixture, IOTP cannot participate in hydration, and it influences the compressive strength by physical filler effect. At the replacement level of $30 \%$ there is a similar trend for compressive strength development in the concrete containing fly ash and IOTP, since fly ash influences the strength mainly by filler effect while its pozzolanic effect has little influence on it. Compared to the smooth round shapes of fly ash, the irregular polyhedral IOTP particles can attach to each other [9], which leads to the higher compressive strength in T0LW at the ages of $1,3,7,28$, 90, and 180 days compared to that in F0LW (30\% instead of cement with fly ash).

\section{The Autogenous Shrinkage of Concrete}

Fig. 5 shows the autogenous shrinkage of concrete with varying $\mathrm{w} / \mathrm{b}$ and fly ash replacement levels. The concrete containing fly ash has a similar trend to that of plain concrete within seven days. The autogenous shrinkage can be separated into the two periods: the rapid growth period (from the initial setting to one day) and stable period (from one to seven days). Autogenous shrinkage primarily occurs within the first day after the initial setting. During this period, concrete shrinks dramatically. There is the greatest rate for the autogenous shrinkage in the $12^{\text {th }}$ hour after the initial setting. At $\mathrm{w} / \mathrm{b}=0.25$, the autogenous shrinkage in the $12^{\text {th }}$ hour accounts for $81.4 \%, 70.0 \%, 67.0 \%$, and $54.2 \%$ of the total for the first seven days in COAS (plain cement), F0AS (10\% instead of cement with fly ash), F1AS ( $20 \%$ instead of cement with fly ash), and F2AS (30\% instead of cement with fly ash). When it comes to the stable period, the aoutogeous shrinkage tends to be stable. The autogenous shrinkage of concrete comes from the chemical shrinkage, which is related to the hydration of the cementitious materials. During the rapid growth period, the matrix of the cementitious materials becomes solid after the initial setting, which restricts the chemical shrinkage and forms a large amount of capillary pores. When the water consumption rate is higher than the water supply rate, the saturated matrix becomes unsaturated, which is known as self-desiccation. The capillary pressure caused by the self-desiccation leads to autogenous shrinkage.

As the fly ash replacement level increases, autogenous shrinkage decreases. At $\mathrm{w} / \mathrm{b}=0.25$, autogenous shrinkage decreases by $41.4 \%, 55.6 \%$, and $73.7 \%$ compared to plain concrete at the age of 12 hours as the replacement level increases from $10 \%$ to $30 \%$. The corresponding decrease is $37.4 \%, 51.1 \%$, and $70.0 \%$ at $w / b=0.35$. There is little pozzolanic reaction from fly ash during the first seven days, thus the early hydration mainly comes from cement. As the replacement level increases, the cement amount decreases, which results in fewer hydration products formed and thus a smaller chemical shrinkage. 
Moreover, the lower water demand of fly ash than cement indicates that the actual water-to-cement ratio increases, which is able to mitigate self-desiccation and autogenous shrinkage. Compared to plain concrete, the capillary pores in fly ash blend concrete are coarser, and larger pores were emptied, which reduces the capillary pressure, the rate of self-desiccation, and thus autogenous shrinkage [23-25].

As w/b increases, the autogenous shrinkage decreases in plain concrete and fly ash blend concrete. As shown in Figs. 5a-c, there is obvious reduction in autogenous shrinkage as the $\mathrm{w} / \mathrm{b}$ increases from 0.25 to 0.35 . As the replacement level increases, the autogenous shrinkage decreases proportionally. Due to the little pozzolanic reaction of fly ash at an early age, the addition of fly ash decreases the amount of cement for hydration, which decreases the filling effect of hydration products in the microstructure. Meanwhile, the actual water-tocement ratio increases, and the content of capillary water increases, which in turn increases the threshold radius, which decreases the capillary pressure and thus the autogenous shrinkage.

Fig. 6 shows autogenous shrinkage in the concrete with varying w/b and IOTP replacement levels within seven days. Compared to Fig. 5, there is similar trend to that in fly ash blend concrete. The rapid growth period and stable period were also observed. As an inert mineral admixture, the addition of IOTP decreases the amount of cement. Thus less hydration products form, which results in smaller chemical shrinkage and thus smaller autogenous shrinkage. And as IOTP replacement level increases, autogenous shrinkage decreases linearly.

The difference of autogenous shrinkage of concrete with different composition is mainly within one day after the initial setting. At this stage the concrete is in a hardening process, the strength and elastic modulus is lower, and creep relaxation is larger, so autogenous shrinkage depends largely on the pore size of the internal pores. In essence, the autogenous shrinkage of concrete is caused by chemical shrinkage due to hydration of cementitious materials. After the initial setting, the rigid paste structure of cement stone is gradually formed and chemical shrinkage is limited, leading to produce a large number of capillary pores in the paste structure of cement. During the hydration process of cement, if water supply speed in the paste internal is less than the water consumption speed, then the water supply speed of inside capillary pores is changed from saturated state to unsaturated state and self-desiccation occurs, leading to negative pressure inside capillary pores and thus causing macroscopic volume shrinkage, which is the autogenous shrinkage of concrete. Capillary pore size is smaller and the relative humidity of internal paste is lower, causing the negative pressure of capillary pores to increase, in turn making autogenous shrinkage greater.

With the decrease of the water-binder ratio, the free water for hydration in the internal paste is reduced, and the internal relative humidity is decreased. On the other hand, the structure of cement stone is dense and the pores are refined. These two aspects lead to increase negative pressure, thus increasing autogenous shrinkage. But when the water-binder ratio and hydration degree of cementitious materials are low, producing chemical shrinkage is less, so the autogenous shrinkage of concrete is not a linear increase with the decreasing water-binder ratio. Mineral admixtures basically do not participate in early hydration reaction, and thus increasing the content of mineral admixtures is equivalent to reducing the amount of cementitious materials early to participate in an early hydration reaction. After adding mineral admixtures, the amount of hydration products decreased and the chemical shrinkage was smaller, and the filling effect of hydration products on internal structure is weakened. With the same water-binder ratio, hydration products need to fill space the same. Therefore, with an increase of mineral admixture content the internal paste structure become loose, the amount of coarse capillary pores increases, the amount of fine capillary pores decreases, the negative pressure of capillary pores decreases, and autogenous shrinkage is reduced. But when the content of mineral admixtures is increased to a certain extent, the "micro powder filling effect" can also play a dense role. So the autogenous shrinkage of concrete is also not linear with the increase of content of mineral admixtures. Due to the decrease of the water-binder ratio and the increase of mineral admixture, it can play a dual role in restraining the autogenous shrinkage of concrete. Therefore, the autogenous shrinkage of concrete can be reduced by adjusting the water-binder ratio and content of mineral admixture under the premise of meeting the concrete strength requirements.

\section{Conclusions}

1) The compressive strength of mortar containing fly ash and IOTP reveals that fly ash and IOTP only have filler effects during the early age hydration of the cementitious composites. As age increases, the pozzolanic reaction of fly ash becomes dramatic. When the content of mineral admixture is greater than $30 \%$, the compressive strength of the mortar block has an influence on the later stage.

2) In the early period of hydration, the physical properties of mineral admixtures has a greater influence on the compressive strength than the chemical properties. The active and inert mineral admixtures show a similar effect on strength.

3) Autogenous shrinkage reveals that there is a similar trend of autogenous shrinkage in concrete containing fly ash and IOTP. At the same w/b, the autogenous shrinkage of concrete decreases linearly as the replacement level increases.

4) The autogenous shrinkage of concrete with different composition showed a rapid increase in the hydration of the first day, followed by a slow increase. Autogenous shrinkage of concrete with different composition shows a rapid increase in one day, the 
shrinkage of concrete in one day is more than the total shrinkage of $80 \%$ in seven days, followed by a slow increase. The decrease of water-binder ratio and the increase of mineral admixture can play a dual role in restraining the autogenous shrinkage of concrete. Within a certain range, with the decrease of the watercement ratio the influence of mineral admixtures on autogenous shrinkage is larger, and with the increase of content of mineral admixture, the influence of the water-binder ratio on autogenous shrinkage is smaller.

\section{Acknowledgements}

The authors gratefully acknowledge financial support from the China Postdoctoral Science Foundation (2016M602082), the Natural Science Foundation of Hebei Province (E2015402057), the Science and Technology Research Project of Higher Education Universities in Hebei Province (ZD2016014), the Comprehensive Utilization of Tailing Resources Key Laboratory of Shaanxi Province (2014SKY-WK001), the Construction Science and Technology Foundation of Hebei Province (2012-136), the Handan Science and Technology Research and Development Plan Program (1621211040-3), and the Jiangxi Postdoctoral Daily Fund Project (2016RC30).

\section{References}

1. NEMATOLLAHI B., SANJAYAN J. Effect of different superplasticizers and activator combinations on workability and strength of fly ash based geopolymer. Materials and Design, 57 (5), 667, 2014.

2. ZHAO H., SUN W., WU X.M., GAO B. The properties of the self-compacting concrete with fly ash and ground granulated blast furnace slag mineral admixtures. Journal of Cleaner Production, 95, 66, 2015.

3. WU Z.M, KHAYAT K.H., SHI C.J. Effect of nano$\mathrm{SiO}_{2}$ particles and curing time on development of fibermatrix bond properties and microstructure of ultra-high strength concrete. Cement and Concrete Research, 95, 247, 2017.

4. AÏTCIN P.C. The durability characteristics of high performance concrete: a review. Cement and Concrete Research, 25 (4-5), 409, 2003.

5. AÏTCIN P.C., WILSON W. Cements of today, concretes of tomorrow. Cement Wapno Beton, 81 (19), 349, 2014 [In Polish]..

6. UPADHYAYA S., GOULIAS D., OBLA K. Maturitybased field strength predictions of sustainable concrete using high-volume fly ash as supplementary cementitious material. Journal of Materials in Civil Engineering, 27 (5), 69, 2015.

7. ANASTASIOU E., FILIKSA K.G., STEFANIDOU M. Utilization of fine recycled aggregates in concrete with fly ash and steel slag. Construction and Building Materials, 50 (5), 154, 2014.

8. MATTIN L.H.J., F WINNEFELD F., TSCHOPP E., MÜLLER C.J., LOTHENBACH B. Influence of fly ash on the hydration of calcium sulfoaluminate cement. Cement and Concrete Research, 95, 152, 2017.
9. YAN P.Y. Mechanism of fly ash's effects during hydration process of composite binder. Journal of the Chinese Ceramic Society, 35 (S1), 167, 2007.

10. TANG P., FLOREA M.V.A., SPIESZ P., BROUWERS H.J.H. Application of thermally activated municipal solid waste incineration (MSWI) bottom ash fines as binder substitute. Cement and Concrete Research, 70, 194, 2016.

11. DAS S., AGUAYO M., SANT G., MOBASHER B., NEITHALATH N. Degree of hydration and gel/space ratio of high-volume fly ash/cement systems. Cement and Concrete Research, 73, 51, 2015.

12. MOON G.D., OH S., CHOI Y.C. Effects of the physicochemical properties of fly ash on the compressive strength of high-volume fly ash mortar. Construction and Building Materials, 124, 1072, 2016.

13. GONZÁLEZ-LÓPEZ J.R., RAMOS-LARA J.F., ZALDIVAR-CADENA A., CHÁVEZ-GUERRERO L., MAGALLANES-RIVERA, R.X., BURCIAGA-DÍAZ O. Small addition effect of agave biomass ashes in cement mortars. Fuel Processing Technology, 133, 35, 2015.

14. SAJEDI F., RAZAK H.A., MAHMUD H.B., SHAFIGH P. Relationships between compressive strength of cement-slag mortars under air and water curing regimes. Construction and Building Materials, 31, 188, 2012.

15. HOANG K., JUSTNES H., GEIKER M. Early age strength increase of fly ash blended cement by a ternary hardening accelerating admixture. Cement and Concrete Research, 81 (3), 59, 2015.

16. PARK J.J., MOOM J.H., PARK G.J., LEE J.H., KIM S.W. An experimental study on charateristics of autogenous shrinkage of HPFRCC considering early age coefficient of thermal expansion. Journal of the Korea AcademiaIndustrial cooperation Society, 16 (5), 3602, 2015.

17. WANG S.Z. Cofired biomass fly ashes in mortar: Reduction of Alkali Silica Reaction (ASR) expansion, pore solution chemistry and the effects on compressive strength. Construction and Building Materials, 82, 123, 2015.

18. METHA P.K. Influence of fly ash characteristics on the strength of portland fly ash mixture. Cement and Concrete Research, 15 (5), 669, 1985.

19. PAYÁ J., MONZO J., PERIS-MORA E. Characterization of spreader stoker coal fly ashes (SSCFA) for their use in cement-based applications. Fuel, 162, 224, 2015.

20. LEE H., VIMONSATIT V., CHINDAPRASIRT P. Mechanical and micromechanical properties of alkali activated fly-ash cement based on nano-indentation. Construction and Building Materials, 107, 95, 2016.

21. SHAIKH F.U.A., SUPIT S.W.M. Compressive strength and durability properties of high volume fly ash (HVFA) concretes containing ultrafine fly ash (UFFA). Construction and Building Materials, 82, 192, 2015.

22. HUANG X.Y., NI W., ZHU L.P., WANG Z.J. Grinding characteristic of Qidashan iron tailings. Journal of University of Science and Technology Beijing, 32 (10), 1253, 2010.

23. XIAO J., CHEN L., XING H. Influence of fly ash and slag powder on autogenous shrinkage of cement mortars. Journal of Building Materials, 14 (5), 604, 2011.

24. YAN P.Y., CHEN Z.C. Autogenous shrinkage of fly ash concrete with different water-binder ratio. Journal of the Chinese Ceramic Society, 42 (5), 585, 2014.

25. YOO S.W., KWON S.J., SANG H.J. Analysis technique for autogenous shrinkage in high performance concrete with mineral and chemical admixtures. Construction and Building Materials, 34 (3), 1, 2012. 